\title{
Intense chemiluminescence from the oxidation of luminol with $m$-chloroperoxybenzoic acid catalyzed by $\mathrm{Mn}(\mathrm{III})$-microperoxidase
}

\author{
Hui-Chun Yeh, Wann-Yin Lin* \\ Department of Chemistry, National Taiwan University, Taipei 106, Taiwan, ROC
}

Received 3 January 2001; received in revised form 13 April 2001; accepted 18 May 2001

\begin{abstract}
We have studied the chemiluminescence (CL) of luminol oxidation with $m$-chloroperoxybenzoic acid (mCPBA) or hydrogen peroxide $\left(\mathrm{H}_{2} \mathrm{O}_{2}\right)$ catalyzed by $\mathrm{Mn}$ (III)-microperoxidase 8 (Mn(III)-MP8) using the stopped-flow technique. The CL involving Mn(III)-MP8 is two to three times as intense as that of the corresponding Fe(III)-MP8, while using mCPBA in place of $\mathrm{H}_{2} \mathrm{O}_{2}$ as the oxidant enhances the $\mathrm{CL}$ by $12-18$-fold at the optimum $\mathrm{pH}(\sim 12)$. The rapid formation of the intermediate, $\mathrm{O}=\mathrm{Mn}$ (IV)-MP8, upon addition of mCPBA to Mn(III)-MP8 will lead to a fast CL cycle. This in turn, will produce an intense $\mathrm{CL}$ of very short duration. The ratio of the peak CL intensity $\left(\mathrm{mCPBA}: \mathrm{H}_{2} \mathrm{O}_{2}\right)$ for the $\mathrm{Mn}(\mathrm{III})-\mathrm{MP} 8$ system remains essentially constant $(\sim 20)$ regardless of the $\mathrm{pH}$ and the concentrations of oxidant and luminol used, provided that the supply of the oxidant and luminol is sufficient. The novel use of Mn(III)-MP8/mCPBA for the CL of luminol oxidation will have a great analytical potential for very sensitive assays. @ 2001 Elsevier Science B.V. All rights reserved.
\end{abstract}

Keywords: Stopped-flow; Chemiluminescence; Mn(III)-microperoxidase 8; Luminol; $m$-Chloroperoxybenzoic acid

\section{Introduction}

Chemiluminescence (CL) based on the oxidation of luminol is one of most extensively studied and best-known CL system [1-3]. The oxidation is usually carried out in an alkaline solution using an oxidant such as hydrogen peroxide [4], hypochlorite [5], permanganate [6], or iodine [7]. The luminol- $\mathrm{H}_{2} \mathrm{O}_{2}$ system is one of the most efficient $\mathrm{CL}$ systems known. The reaction is catalyzed by peroxidases [8] (e.g. horseradish peroxidase (HRP)), metal ions [9] (e.g. $\mathrm{Co}(\mathrm{II}), \mathrm{Fe}(\mathrm{II}), \mathrm{Cu}(\mathrm{II})$ ), or metal-containing

\footnotetext{
* Corresponding author. Tel.: +886-2-23638001; fax: +886-2-23636359.

E-mail address: wylin@chem50.ch.ntu.edu.tw (W.-Y. Lin).
}

species $[10,11]$ (e.g. $\mathrm{Fe}(\mathrm{CN})_{6}{ }^{3-}$, iron porphyrins). Owing to its intense CL, the luminol- $\mathrm{H}_{2} \mathrm{O}_{2}-\mathrm{HRP}$ system has been employed in many CL assays, such as antioxidants [12], $p$-coumaric acid in beers [13], peroxidases [14], and phenolic enhancers [15]. The assay is usually carried out at $\mathrm{pH} \sim 8.5$ because of the low activity and stability of HRP at high $\mathrm{pH}$. To conduct the oxidation of luminol by $\mathrm{H}_{2} \mathrm{O}_{2}$ at high $\mathrm{pH}$ (10-13), microperoxidase (MP) has been used to replace HRP as the catalyst. This CL system has been employed in the detection of antioxidants $[16,17]$.

The key step for producing CL by peroxidasecatalyzed oxidation of luminol by $\mathrm{H}_{2} \mathrm{O}_{2}$ is the production of luminol radicals from the reaction of luminol with the reactive intermediates which are formed by the oxidation of peroxidase with $\mathrm{H}_{2} \mathrm{O}_{2}$ [8]. The 
replacement of $\mathrm{Fe}(\mathrm{III})$ in MP8 with $\mathrm{Mn}$ (III) yields Mn(III)-MP8, which is also capable of forming a reactive intermediate $(\mathrm{O}=\mathrm{Mn}(\mathrm{IV})-\mathrm{MP} 8)$ upon oxidation with $\mathrm{H}_{2} \mathrm{O}_{2}$ [18]. Moreover, $\mathrm{Mn}(\mathrm{III})-\mathrm{MP} 8$ shows high activity at high $\mathrm{pH}$ (with an optimum $\geq 12$ ) [19]. Therefore, Mn(III)-MP8 is expected to be an efficient catalyst in inducing the $\mathrm{CL}$ of luminol- $\mathrm{H}_{2} \mathrm{O}_{2}$ at high $\mathrm{pH}$. It is known that $m$-chloroperoxybenzoic acid (mCPBA) is much more efficient than $\mathrm{H}_{2} \mathrm{O}_{2}$ in transferring an oxygen atom to heme or porphyrin iron(III) to form a reactive intermediate [20]. Rapid formation of the intermediate will lead to a fast CL cycle, which in turn will give rise to intense $\mathrm{CL}$ in a given time. Thus, using mCPBA as the oxidant is expected to induce more intense luminol $\mathrm{CL}$ than by using $\mathrm{H}_{2} \mathrm{O}_{2}$. In this paper, we have studied the $\mathrm{CL}$ of $\mathrm{Mn}$ (III)-MP8-catalyzed oxidation of luminol using either $\mathrm{H}_{2} \mathrm{O}_{2}$ or mCPBA as the oxidant by the stopped-flow technique. Time-resolved absorption spectra for $\mathrm{Mn}$ (III)-MP8 upon addition of $\mathrm{H}_{2} \mathrm{O}_{2}$ or mCPBA were measured to unravel the differences in $\mathrm{CL}$ intensities induced by the two oxidants. We have also investigated the effects of $\mathrm{pH}$ and the concentrations of oxidants and luminol on the CL reactions involving Mn(III)-MP8.

\section{Experimental}

\subsection{Materials}

Horse heart cytochrome $c$, pepsin, trypsin, sodium phosphate, sodium hydrogenphosphate, luminol (5-amino-2,3-dihydrophthalazine-1,4-dione), and TRIZMA ${ }^{\circledR}$ base (tris[hydroxymethyl] aminomethane, Tris) were purchased from Sigma (St. Louis, MO, USA). Sodium carbonate, manganese(II) acetate, ammonium acetate and mCPBA were obtained from Acros Organics Company (Geel, Belgium). Sephadex G-25 was purchased from Pharmacia LKB Biotechnology. All reagents were of the highest available purity. Ultra high purity deionized water was obtained from a Milli-Q purification system $\left(18.2 \mathrm{M} \Omega \mathrm{cm}^{-1}\right.$, Millipore, Tokyo). The stock solution of hydrogen peroxide (Fluka, Seelze, Germany) was prepared by volumetric dilution of $30 \%(\mathrm{w} / \mathrm{w}) \mathrm{H}_{2} \mathrm{O}_{2}$ by $\mathrm{pH} 7.0$ phosphate buffer. The concentration of $\mathrm{H}_{2} \mathrm{O}_{2}$ was determined daily by measuring the absorbance at
$240 \mathrm{~nm}$ on a U-3210 spectrophotometer (Hitachi, Tokyo) using $\varepsilon_{240}=39.4 \mathrm{M}^{-1} \mathrm{~cm}^{-1}$ [21]. The stock solutions of luminol $(2 \mathrm{mM})$ and mCPBA $(1 \mathrm{mM})$ were prepared by dissolving precisely weighed solid in $5 \mathrm{mM}$ carbonate ( $\mathrm{pH} 10.7)$ and phosphate ( $\mathrm{pH} 7.0)$ buffer, respectively.

\subsection{The preparation of $M n(I I I)-M P 8$}

Fe(III)-MP8 was prepared from the proteolytic digestion of cytochrome $c$ with pepsin and trypsin by a known procedure [22]. Mn(III)-MP8 was synthesized according to the procedure in the literature [18]. Lyophilized Fe(III)-MP8 in a PTFE reaction container was attached to a hydrogen fluoride line and cooled in a dry ice-acetone bath. Sufficient hydrogen fluoride $(\sim 5 \mathrm{ml})$ was condensed into the vessel to cover the $\mathrm{Fe}(\mathrm{III})-\mathrm{MP} 8$ powder. After $5 \mathrm{~min}$, hydrogen fluoride was removed under vacuum and a purple residue remained in the vessel. The residue was redissolved in $1 \mathrm{M}$ ammonium acetate buffer $(\mathrm{pH}$ 5.0) and the solution was passed down a Sephadex G-25 column to remove the salts. The solution of metal-free MP8 was used immediately for the metalation reaction by adding manganese(II) acetate. The mixture was warmed to $40^{\circ} \mathrm{C}$ in a water bath for $2 \mathrm{~h}$, then removed and allowed to stand in the dark for 2 days. The product was purified by liquid chromatography with a $1 \mathrm{~cm} \times 25 \mathrm{~cm}$ reverse-phase (C-18) column. The concentration of Mn(III)-MP8 was determined from the absorbance at $368 \mathrm{~nm}$ using $\varepsilon_{368}=1.1 \times 10^{5} \mathrm{M}^{-1} \mathrm{~cm}^{-1}$ at $\mathrm{pH} 2.0$ [18].

\subsection{Instruments and methods}

All the experiments (CL, change in absorbance and time-resolved absorption spectra) were performed on a stopped-flow spectrofluorimeter (SF-61, Hitech Scientific, Salisbury, UK), which contained a sample handling unit (SHU-61), a monochromator (MG-60) for wavelength selection, a dual detection accessory (OPT-680) for absorption and fluorescence measurements, a photodiode array assembly (MG-6010) for taking the time-resolved absorption spectra, a $75 \mathrm{~W}$ xenon lamp (L-2194-02, Hamamatsu, Tokyo) as the light source, and a circulating water bath for temperature control. The sample cell was made of fused silica with dimensions of $10 \mathrm{~mm} \times 1.5 \mathrm{~mm} \times 1.5 \mathrm{~mm}$. 
When doing the CL experiments, the light source was switched off and the fluorescence mode was used. The photomultiplier tube (PMT, R928, Hamamatsu) voltage was set at $500 \mathrm{~V}$. The Mn(III)-MP8 solution was stored in one syringe while the luminol-oxidant mixture was stored in the other. The CL intensity versus time profiles were recorded after 1:1 (v/v) mixing of the solutions in two syringes under a pneumatic pressure of $55 \mathrm{psi}$. The flow rate of the mixed solution was $10 \mathrm{ml} \mathrm{s}^{-1}$ and the dead time was $2 \mathrm{~ms}$. All solutions (except for the $\mathrm{pH}$-dependence experiments) were prepared in $5 \mathrm{mM}$ carbonate buffer at $\mathrm{pH} 12.0$. The $\mathrm{pH}$-dependence experiments were carried out in $5 \mathrm{mM}$ phosphate buffer and the $\mathrm{pH}$ values were adjusted with saturated $\mathrm{NaOH}$ or concentrated $\mathrm{HCl}$ using a pH meter (Model 6071, Jenco Electronics Ltd., Taipei). For measuring the rate of the intermediate formation, the change in absorbance at $404 \mathrm{~nm}$ was monitored continuously after mixing $\mathrm{Mn}$ (III)-MP8 and oxidant (mCPBA or $\mathrm{H}_{2} \mathrm{O}_{2}$ ) from two separate syringes. The experiments were operated in the absorption mode and the PMT voltage was set at $200 \mathrm{~V}$. The built-in software of the stopped-flow instrument allows multiple exponential fitting of the traces. All the stopped-flow experiments were carried out at $25^{\circ} \mathrm{C}$.

\section{Results and discussion}

\subsection{Stopped-flow CL profiles}

Stopped-flow has been utilized to detect the short-lived CL, which ensures rapid and reproducible mixing of reagents and allows full intensity versus time profiles to be obtained. The stopped-flow method is also suitable for analyzing the CL reaction kinetics [23]. The CL intensity versus time profiles for the oxidation of $50 \mu \mathrm{M}$ luminol with $10 \mu \mathrm{M}$ mCPBA or $10 \mu \mathrm{M} \mathrm{H}_{2} \mathrm{O}_{2}$ catalyzed by $2.4 \mu \mathrm{M} \mathrm{Mn}(\mathrm{III})-\mathrm{MP} 8$ in $5.0 \mathrm{mM}$ carbonate buffer at $\mathrm{pH} 12.0$ are shown in Fig. 1. A very intense CL with much shorter duration of time was observed when using mCPBA as an oxidant as compared to $\mathrm{H}_{2} \mathrm{O}_{2}$. The relative peak $\mathrm{CL}$ intensity $\left(\mathrm{mCPBA} / \mathrm{H}_{2} \mathrm{O}_{2}\right.$ ) was determined to be $19.3 \pm 0.3(n=10)$. The $\mathrm{CL}$ process involving mCPBA occurs very rapidly (within $1 \mathrm{~s}$ ). Multiple exponential fitting of the stopped-flow traces using the built-in software of the instrument allows the area

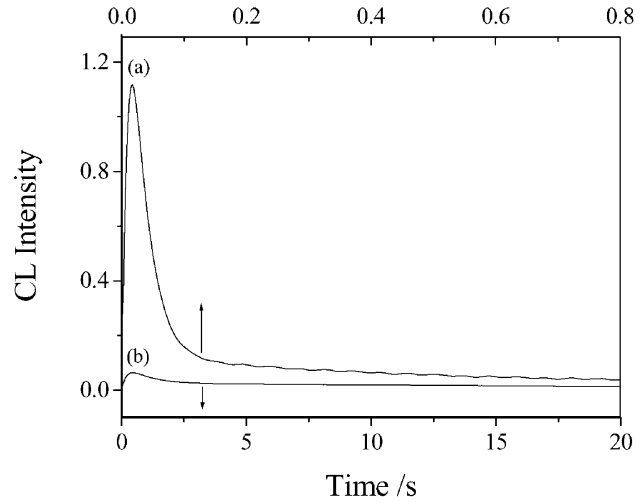

Fig. 1. CL intensity vs. time profiles for the Mn(III)-MP8-catalyzed oxidation of luminol in $5.0 \mathrm{mM}$ carbonate buffer at $\mathrm{pH} 12.0$ using (a) mCPBA or (b) $\mathrm{H}_{2} \mathrm{O}_{2}$ as the oxidant. The concentrations of $\mathrm{Mn}$ (III)-MP8, oxidant and luminol are 2.4, 10.0 and $50.0 \mu \mathrm{M}$, respectively. The upper time scale (also in s) was used for the much faster $\mathrm{CL}$ reaction involving mCPBA.

under the curve, which is a measure of the total CL intensity, to be estimated. The area for trace (a) is $\sim 40 \%$ that of trace (b). The small total intensity for the CL involving mCPBA may result from different CL efficiencies caused by the two different oxidants, since the oxidant is also involved in the subsequent reactions of luminol radicals leading to CL. For the $\mathrm{CL}$ involving mCPBA and $\mathrm{H}_{2} \mathrm{O}_{2}$, the duration time differs by more than 20 -fold, while the total emitted CL differs by only $\sim 40 \%$. Evidently, the shorter the duration time the greater the CL intensity.

\subsection{Rates for the formation of intermediates}

Since the luminol radical is the key component for the production of CL [8], any factor that facilitates the formation of the intermediates and/or the luminol radicals will tend to increase the CL intensity. Thus, measuring the rate of formation of the intermediate is important in understanding the relative CL intensity and duration time. The formation of the intermediates can be monitored by the stopped-flow technique using the photodiode array detection. Fig. 2A shows the time-resolved absorption spectra during the reaction of $2.4 \mu \mathrm{M} \mathrm{Mn}$ (III)-MP8 and $10 \mu \mathrm{M} \mathrm{H}_{2} \mathrm{O}_{2}$ in $5.0 \mathrm{mM}$ carbonate buffer at $\mathrm{pH}$ 12.0. Upon addition of $\mathrm{H}_{2} \mathrm{O}_{2}$, a gradual disappearance of the bands at 368 and $464 \mathrm{~nm}$ for Mn(III)-MP8 and 

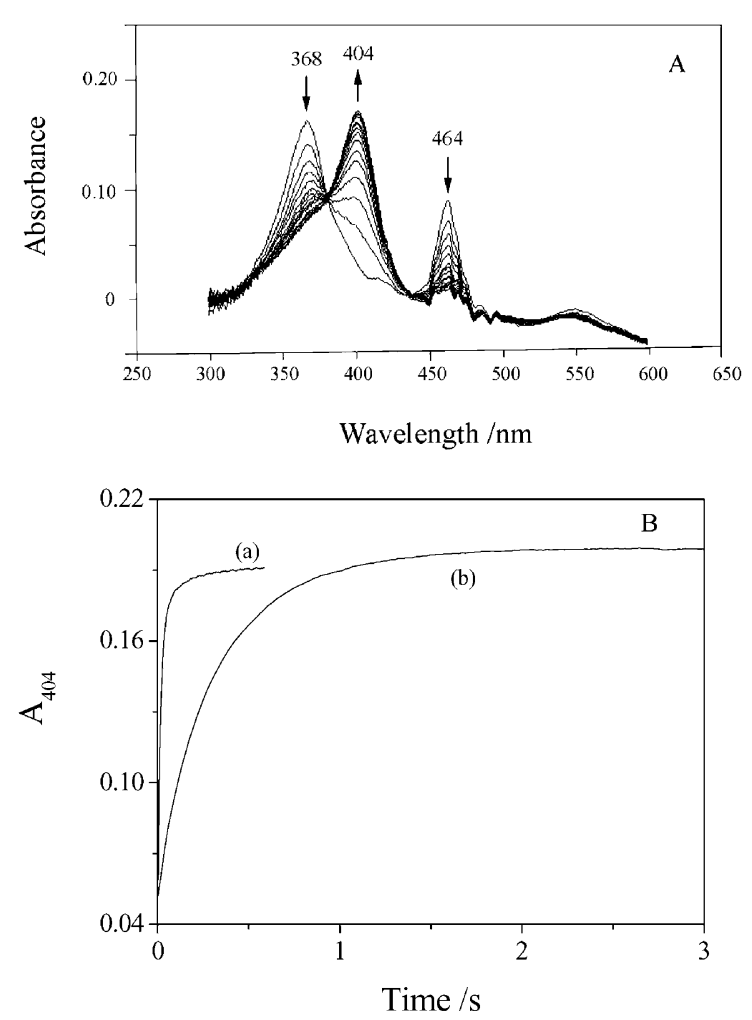

Fig. 2. (A) Stopped-flow time-resolved difference spectra for the oxidation of $\mathrm{Mn}(\mathrm{III})-\mathrm{MP} 8$ with $\mathrm{H}_{2} \mathrm{O}_{2}$ at $\mathrm{pH}$ 12.0. The time interval per trace is $0.2 \mathrm{~s}$; (B) time courses of the changes in absorbance at $404 \mathrm{~nm}\left(A_{404}\right)$ for the oxidation of Mn(III)-MP8 with (a) mCPBA and (b) $\mathrm{H}_{2} \mathrm{O}_{2}$ at $\mathrm{pH}$ 12.0. The single-exponential fitting of the stopped-flow traces yields $A_{404}=0.197-0.144 \mathrm{e}^{-60.03 t}$ for trace (a) and $A_{404}=0.196-0.145 \mathrm{e}^{-1.29 t}$ for trace (b) $(t=$ time, s). The fitted and experimental curves are indistinguishable. The concentrations of reagents are the same as those given in Fig. 1.

the concomitant appearance of a new band at $404 \mathrm{~nm}$ with sharp isosbestic points at 389 and $418 \mathrm{~nm}$ were observed. These spectral features are characteristics of the intermediate $\mathrm{O}=\mathrm{Mn}(\mathrm{IV})-\mathrm{MP} 8$ [18]. The same spectral changes were also observed when using mCPBA as the oxidant (data not shown), suggesting the formation of the same intermediate. The rate for the formation of the intermediate can be determined by following the change in absorbance at $404 \mathrm{~nm}$, as illustrated in Fig. 2B. The relative rate constant (mCPBA $/ \mathrm{H}_{2} \mathrm{O}_{2}$ ), obtained from the single-exponential fitting of the stopped-flow traces, is $46.5 \pm 0.9$ ( $n=$ 10). Thus, a fast formation of the intermediate leads to a fast CL cycle, which in turn will give rise to a large CL intensity in a given time, consistent with the conclusion drawn from Fig. 1. It is noted that the relative peak CL intensity (19.3) is only $42 \%$ of the relative rate constant of intermediate formation (46.5). The result suggests that the CL efficiency, which is determined by the subsequent reactions of luminol radicals and the oxidant, for mCPBA is only $42 \%$ that for $\mathrm{H}_{2} \mathrm{O}_{2}$. The result also supports a discrepancy of $\sim 40 \%$ in the relative total $\mathrm{CL}$ emission for the two oxidants.

\section{3. $p H$ dependence of $C L$ intensity}

Fig. 3 shows the $\mathrm{pH}$ dependence of the peak CL intensity for the oxidation of $50 \mu \mathrm{M}$ luminol with mCPBA or $\mathrm{H}_{2} \mathrm{O}_{2}$ catalyzed by $\mathrm{Mn}(\mathrm{III})-\mathrm{MP} 8$ or $\mathrm{Fe}(\mathrm{III})-\mathrm{MP} 8$ in $5.0 \mathrm{mM}$ phosphate buffer. Extremely weak $\mathrm{CL}$ was observed at $\mathrm{pH}<10$ for all systems. Much more intense CL occurs at $\mathrm{pH} 10-13$ with a maximum at ca. $\mathrm{pH} 12$. The $\mathrm{pH}$ dependence of CL involving Mn(III)-MP8 and Fe(III)-MP8 is very similar. It is also noted that the peak CL intensity involving mCPBA is much stronger than that of $\mathrm{H}_{2} \mathrm{O}_{2}$ in the $\mathrm{pH}$ range $10-13$. The ratio of the peak $\mathrm{CL}$ intensity at $\mathrm{pH} 12.0$ for $\mathrm{Mn}(\mathrm{III})-\mathrm{MP} 8$ relative to $\mathrm{Fe}(\mathrm{III})-\mathrm{MP} 8$ is 2.1 and 3.1 for $\mathrm{H}_{2} \mathrm{O}_{2}$ and mCPBA, respectively, while the ratio (mCPBA: $\mathrm{H}_{2} \mathrm{O}_{2}$ ) is 12.3 and 18.0 for Fe(III)-MP8 and Mn(III)-MP8, respectively. Moreover, the relative $\mathrm{CL}$ intensity (mCPBA: $\mathrm{H}_{2} \mathrm{O}_{2}$ )

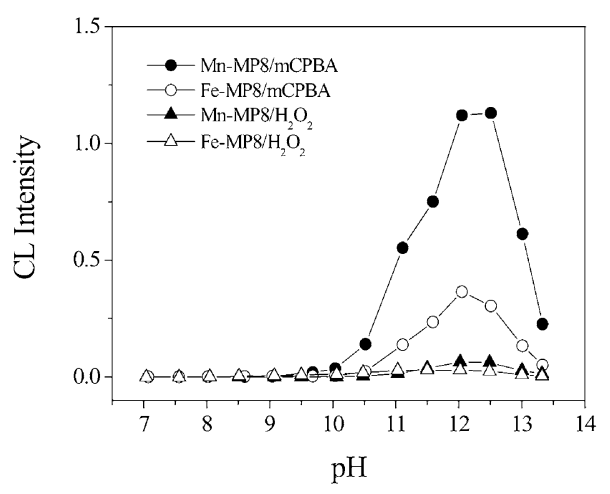

Fig. 3. $\mathrm{pH}$ dependence of the peak CL intensity of Fe(III)- and $\mathrm{Mn}$ (III)-MP8-catalyzed luminol oxidation in $5.0 \mathrm{mM}$ phosphate buffer using either mCPBA or $\mathrm{H}_{2} \mathrm{O}_{2}$ as the oxidant. The reaction conditions are the same as those given in Fig. 1. The four combinations of the CL systems are indicated in the figure. 


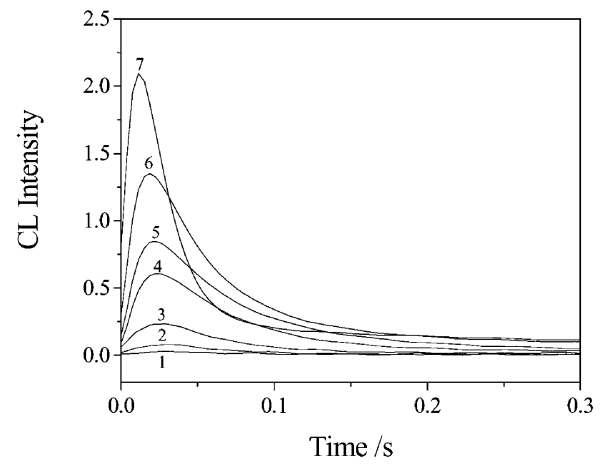

Fig. 4. CL intensity vs. time profiles for the reactions of $2.4 \mu \mathrm{M}$ $\mathrm{Mn}$ (III)-MP8 and $50 \mu \mathrm{M}$ luminol in $5.0 \mathrm{mM}$ carbonate buffer (pH 12.0) at various concentrations of mCPBA (from traces 1 to 7): $0.5,1,2,4,6,10$, and $20 \mu \mathrm{M}$.

involving $\mathrm{Mn}(\mathrm{III})-\mathrm{MP} 8$ remains fairly constant (18-22) in the $\mathrm{pH}$ range $10-13$.

\subsection{Effect of oxidant concentration on the CL intensity}

Fig. 4 shows the CL intensity versus time profiles for the reaction of $2.4 \mu \mathrm{M} \mathrm{Mn}$ (III)-MP8 and $50 \mu \mathrm{M}$ luminol in $5.0 \mathrm{mM}$ carbonate buffer $(\mathrm{pH} \mathrm{12.0)}$ at various concentrations $(0.5-20 \mu \mathrm{M})$ of mCPBA. The CL intensity increases rapidly as the concentration of mCPBA increases. On the other hand, the duration time remains nearly the same when the concentration of mCPBA is $<10 \mu \mathrm{M}$, whereas a significant reduction in duration was observed when the concentration of mCPBA is $>20 \mu \mathrm{M}$. When the concentration of mCPBA is $<10 \mu \mathrm{M}, \mathrm{mCPBA}$ is the limiting reagent and the CL intensity is proportional to the concentration of mCPBA, while the duration remains essentially the same. When the concentration of mCPBA is $>20 \mu \mathrm{M}$, luminol becomes the limiting reagent. Under this circumstance, several factors affecting the CL intensity and duration time need to be considered. Firstly, an increase in the concentration of mCPBA will accelerate the CL cycle and, hence, enhance the peak CL intensity. Secondly, the limited supply of luminol will reduce the duration time and also limit the increase in CL intensity. Thirdly, the instability of the highly reactive intermediate at high concentration of oxidant [24] will diminish the CL intensity
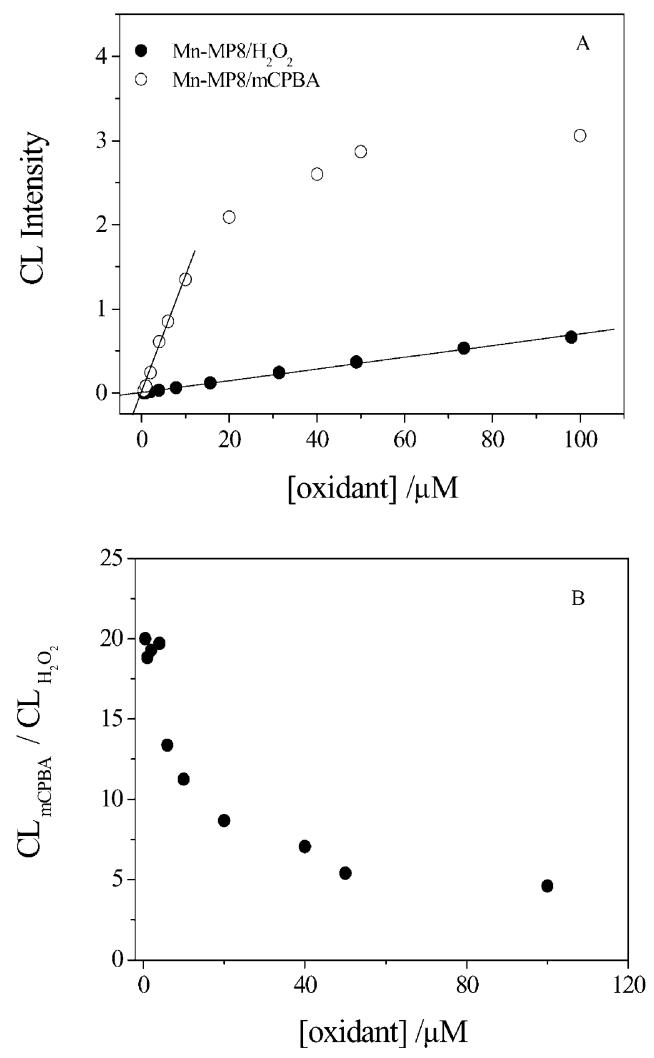

Fig. 5. (A) The effect of the concentration of $\mathrm{H}_{2} \mathrm{O}_{2}$ (closed circle) and mCPBA (open circle) on the peak CL intensity of the $\mathrm{Mn}$ (III)-MP8-catalyzed luminol oxidation in $5 \mathrm{mM}$ carbonate buffer at $\mathrm{pH} 12.0$; (B) the relative $\mathrm{CL}$ intensity $\left(\mathrm{mCPBA}: \mathrm{H}_{2} \mathrm{O}_{2}\right.$ ) for the data in (A) at various concentration of oxidant. The rest of the reaction conditions are the same as those in Fig. 1.

and the duration. Thus, the observed CL profile will be determined by the relative contributions of these three factors. Similar trends in CL profiles were also observed when using $\mathrm{H}_{2} \mathrm{O}_{2}$ as the oxidant (data not shown). However, because of the much slower CL cycle, the reduction in duration was not observed until the concentration of $\mathrm{H}_{2} \mathrm{O}_{2}$ was $>100 \mu \mathrm{M}$. The peak $\mathrm{CL}$ intensities at various concentrations $(0.5-100 \mu \mathrm{M})$ of the oxidants (mCPBA or $\mathrm{H}_{2} \mathrm{O}_{2}$ ) are illustrated in Fig. 5A. A linear dependence was observed for $\mathrm{H}_{2} \mathrm{O}_{2}$ $(0.5-100 \mu \mathrm{M})$ and mCPBA $(0.5-10 \mu \mathrm{M})$. The deviation from linearity when the concentration of mCPBA is greater than $10 \mu \mathrm{M}$ is due to the limited supply of luminol and possibly partial degradation of the intermediate. The rapid CL cycle for mCPBA will result 


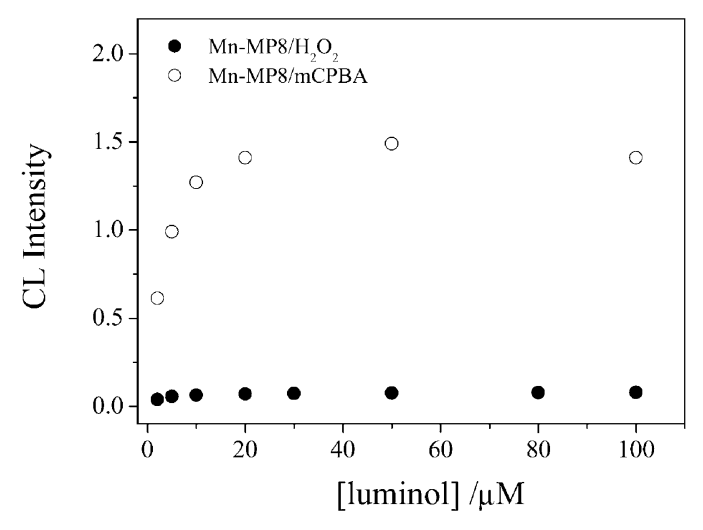

Fig. 6. The effect of the concentration of luminol on CL intensity of the Mn(III)-MP8-catalyzed luminol oxidation in $5 \mathrm{mM}$ carbonate buffer at $\mathrm{pH} 12.0$ using $\mathrm{H}_{2} \mathrm{O}_{2}$ (closed circle) or mCPBA (open circle) as the oxidant. The rest of the reaction conditions are the same as those in Fig. 1.

in a rapid depletion of luminol. The relative peak CL intensity (mCPBA: $\mathrm{H}_{2} \mathrm{O}_{2}$ ) at each concentration of oxidant has also been calculated using the data in Fig. $5 \mathrm{~A}$ and the results are shown in Fig. 5B. The ratio remains fairly constant $(\sim 20)$ as the concentration of oxidant is $<10 \mu \mathrm{M}$ and drops rapidly at high concentration of oxidant due to the downward curvature for the plot of CL involving mCPBA in Fig. 5A.

\subsection{Effect of luminol concentration on the CL intensity}

Fig. 6 shows the observed peak CL intensity as a function of luminol concentration $(2-100 \mu \mathrm{M})$ for the reactions of $2.4 \mu \mathrm{M} \mathrm{Mn(III)-MP8} \mathrm{and} 10 \mu \mathrm{M}$ of mCPBA or $10 \mu \mathrm{M} \mathrm{H}_{2} \mathrm{O}_{2}$ in $5 \mathrm{mM}$ carbonate buffer at $\mathrm{pH}$ 12.0. The peak CL intensity increases as the concentration of luminol increases and curves downward at high concentration of luminol. Thus, the maximum $\mathrm{CL}$ intensity was achieved when the relative concentration of luminol to oxidant is nearly 3. Excess luminol (greater than three times the concentration of oxidant) will not enhance the CL intensity further because of the saturation of the $\mathrm{CL}$ signal. The ratio of the relative peak CL intensity (mCPBA: $\mathrm{H}_{2} \mathrm{O}_{2}$ ) was found to be relatively constant (16-20) over the whole concentration range.

In summary, Mn(III)-MP8 is an efficient catalyst for the $\mathrm{CL}$ of luminol oxidation and its $\mathrm{CL}$ is two to three times as intense as that of the corresponding $\mathrm{Fe}$ (III)-MP8 system. The use of mCPBA in place of $\mathrm{H}_{2} \mathrm{O}_{2}$ as the oxidant in the $\mathrm{CL}$ reaction involving $\mathrm{Fe}(\mathrm{III})-$ or Mn(III)-MP8 further increases the CL intensity by $12-18$-fold. Using mCPBA to replace $\mathrm{H}_{2} \mathrm{O}_{2}$ also causes a tremendous increase (46.5-fold) in the rate of intermediate formation in the Mn(III)-MP8 system. The rapid formation of intermediate (i.e. a fast CL cycle) will lead to a dramatic enhancement of the CL intensity. However, the increase in peak CL intensity upon replacing $\mathrm{H}_{2} \mathrm{O}_{2}$ with mCPBA is only $42 \%$ that of the increase in the rate of intermediate formation. Moreover, the total CL emission when using mCPBA as the oxidant is only $\sim 40 \%$ that of using $\mathrm{H}_{2} \mathrm{O}_{2}$. These results suggest that the CL efficiency for the subsequent reactions of luminol radicals with mCPBA is $\sim 60 \%$ smaller than that with $\mathrm{H}_{2} \mathrm{O}_{2}$. The ratio of the peak CL intensity (mCPBA: $\mathrm{H}_{2} \mathrm{O}_{2}$ ) for the Mn(III)-MP8 system remains essentially constant ( 20) regardless of the $\mathrm{pH}$ and the concentrations of oxidant and luminol used, provided that the supply of the oxidant and luminol is sufficient. Thus, the dramatic enhancement of CL in replacing $\mathrm{H}_{2} \mathrm{O}_{2}$ with mCPBA is quite general under most conditions. The novel use of $\mathrm{Mn}$ (III)-MP8/mCPBA for the CL of luminol oxidation will have an analytical potential for very sensitive assays. For example, using mCPBA as the oxidant is far superior to $\mathrm{H}_{2} \mathrm{O}_{2}$ for the $\mathrm{CL}$ detection of luminol, as seen in Fig. 6.

\section{Acknowledgements}

The authors thank the National Science Council of ROC for financial support (NSC 89-2113-M-002-029).

\section{References}

[1] K. Robards, P.J. Worsfold, Anal. Chim. Acta 266 (1992) 147.

[2] L.J. Kricka, Anal. Chem. 67 (1995) 499R.

[3] A.R. Bowie, M.G. Sanders, P.J. Worsfold, J. Biolumin. Chemilumin. 11 (1996) 119.

[4] H.O. Albrecht, Z. Phys. Chem. 136 (1928) 321.

[5] D. Gonzalez-Robledo, M. Silva, D. Perez-Bendito, Anal. Chim. Acta 228 (1990) 123.

[6] A.K. Babko, N.M. Lukovskaya, Dopov. Akad. Nauk. Ukr. RSR 619 (1962).

[7] A.K. Babko, L.V. Markova, N.M. Lukovskaya, Zh. Anal. Khim. 23 (1968) 401. 
[8] P.M. Easton, A.C. Simmonds, A. Rakishev, A.M. Egorov, L.P. Candeias, J. Am. Chem. Soc. 118 (1996) 6619.

[9] W.R. Seitz, D.M. Hercules, in: M.J. Cormier, D.M. Hercules, J. Lee (Eds.), Chemiluminescence and Bioluminescence, Plenum Press, New York, 1973, pp. 427-449.

[10] H. Kubo, A. Toriba, Anal. Chim. Acta 353 (1997) 345.

[11] P. Jones, N.R. Scowen, Photochem. Photobiol. 45 (1987) 283.

[12] T.P. Whitehead, G.H.G. Thorpe, S.R.J. Maxwell, Anal. Chim. Acta 266 (1992) 265.

[13] F.G. Sanchez, A.N. Diaz, J.A.G. Garcia, Anal. Chim. Acta 310 (1995) 399.

[14] H. Arakawa, M. Maeda, A. Tsuji, Anal. Biochem. 97 (1979) 248.

[15] F.G. Sanchez, A.N. Diaz, J.A.G. Garcia, J. Lumin. 65 (1995) 33.

[16] O. Hirayama, M. Takagi, K. Hukumoto, S. Katoh, Anal. Biochem. 247 (1997) 237.
[17] A. Dapkevicius, T.A. van Beek, H.A.G. Niederlander, A. de Groot, Anal. Chem. 71 (1999) 736.

[18] D.W. Low, S. Abedin, G. Yang, J.R. Winkler, H.B. Gray, Inorg. Chem. 37 (1998) 1841.

[19] J.L. Primus, M.G. Boersma, D. Mandon, S. Voeren, C. Veeger, R. Weiss, I.M. Rietjens, J. Biol. Inorg. Chem. 4 (1999) 274.

[20] W.A. Lee, L.-C. Yuan, T.C. Bruice, J. Am. Chem. Soc. 110 (1988) 4277.

[21] J.-S. Wang, H.K. Baek, H.E. van Wart, Biochem. Biophys. Res. Commun. 179 (1991) 1320.

[22] J. Aron, D.A. Baldwin, M.M. Marques, J.M. Pratt, P.A. Adams, J. Inorg. Biochem. 27 (1986) 227.

[23] D. Gonzalez-Robledo, M. Silva, D. Perez-Bendito, Anal. Chim. Acta 217 (1989) 239.

[24] J.H. Spee, M.G. Boersma, C. Veeger, B. Samyn, J. van Beeumen, G. Warmerdam, G.W. Canters, W.M.A.M. van Dongen, I.M.C.M. Rietjens, Eur. J. Biochem. 241 (1996) 241. 